\title{
Sistem Pendidikan Islam dalam Kerangka Nasionalis-Religius Berbasis rahmatan lil alamin
}

\author{
Jaenuri \\ UNU Surakarta \\ jaenuri886@gmail.com
}

\begin{abstract}
Islam can be accepted by the Indonesian people in a relatively short time, because it is in accordance with the sociological style of diversity that has taken root in Indonesia. The process of Islamization in Indonesia also involves several components, such as traders, clerics, kingdoms, and Islamic educational institutions, which allow for even distribution to various segments of society. Islam is like giving a new alternative to lasting coral feudalism by offering equality of dignity, dignity, and upholding justice. The concept of education which undermines religious and nationalist values is considered important because the reality is often found in the dichotomous separation between them. Whereas Islamic education carries the mission of rahmatalil alamin, in the midst of the current Islamophobia as a religion that is imaged closed and radical. The purpose of this paper is to get the concept of mengani Islamic education system within the framework of nationalism-religious based rahmatan lil alamin. Study by proposing a correlation of arguments and arguments, between the education system and the Qur'anic verses and relevant hadiths. As a result, a religious nationalist-based educational framework has a strong foundation of textual, psychological, historical and sociological Research.
\end{abstract}

Kata kunci: Islamic education, nationalits, religious, rahmatan lil 'alamin

\begin{abstract}
Abstrak: Agama Islam dapat diterima oleh masyarakat Indonesia dalam waktu yang relatif singkat antara lain karena ajarannya sesuai dengan corak sosiologis keragaman yang telah mengakar di Indonesia. Proses Islamisasi di Indonesia juga melibatkan beberapa komponen, seperti pedagang, ulama, kerajaan, dan lembaga pendidikan Islam, yang memungkinkan merata pada berbagai segmen masyarakat. Islam seperti memberi alternatif baru bagi coral feodalis yang telah melanggeng dengan menawarkan persamaanm harkat, martabat, dan menjunjung tinggi keadilan. Konsep pendidikan yang mangrusutmakan nilai religiusitas dan nasionalis dirasa penting karena realitasnya sering didapati pemisahan dikotomis keduanya. Sedangkan pendidikan Islam mengusung misi rahmatalil alamin, ditengah arus Islamophobia sebagai agama yang dicitrakan tertutup dan radikal. Tujuan penulisan ini adalah untuk mendapatkan konsep mengani sistem pendidikan Islam dalam kerangka nasionalis-religius berbasis rahmatan lil alamin. Penelaahan dengan mengajukan korelasi dalil dan argumentasi, antara sistem pendidikan dengan ayat-ata Al-Quran maupun Hadis yang relevan. Hasilnya, kerangka pendidikan berbasis nasionalis religius memiliki landasan yang kuat dari penelusuran teks, psikologis, historis maupun sosiologis.
\end{abstract}

Kata kunci: pendidikan Islam, nasionalis, religius, rahmattan lil 'alamin 


\section{A. Pendahuluan}

Keberadaan manusia di dunia ini saling membutuhkan. Tidak ada satu manusiapun yang lahir hingga dewasa dengan daya upayanya sendiri, semua membutuhkan orang lain. Maka benar jika Aristoteles sebagaimana dikutip Wandhi bahwa manusia adalah zoon politicon yang artinya makhuk yang berkelompok.' Dalam memenuhi kebutuhan hidupnya, manusia membentuk kelompok dari yang terkecil hingga terbesar. Kelompok keluarga sebagai item terkecil kemudian masyarkat dan negara.

Indonesia sebelum merdeka terdiri dari kerajaan-kerajaan. Masyarakatnya hidup berkelompok di bawah kuasa para raja. Barulah kemudian dalam perkembangannya Indonesia menjadi sebuah bangsa. Terbentuknya sebuah bangsa tidak lepas dari adanya kesepakatan untuk mencapai tujuan bersama. Lebih lanjut Wandhi menjelaskan perlu adanya identitas dalam menyatukan masyarakat bangsa, sebagaimana dikutip dari perkataa Ramlan yaitu primordial, sakral, tokoh, bhineka tunggal ika, sejarah, perkembangan ekonomi, dan kelembagaan. ${ }^{2}$

Awal sejarahnya, masyarakat Indonesia sudah mengenal adanya kepercayaan terhadap benda-benda yang dianggapnya memiliki kekuatan. Sedikit demi sedikit kepercayaan itu terkikis dengan datangnya agama hindu dan budha. Hingga sekitar abad ke-7 datanglah agama Islam melalui para dai dari luar. Masuknya Islam ke Indonesia atas andilnya beberapa komponen yaitu para pedagang, ulama, kerajaan, dan lembaga pendidikan Islam. ${ }^{3}$ Agama Islam dapat diterima oleh masyarakat Indonesia dalam waktu yang relatif singkat. Hal ini dikarenakan ajaran agama islam adalah sesuai dengan fitrah manusia. Sebagaimana Abdul Kodir menjelaskan bahwa faktor-faktor yang menyebabkan agama Islam mudah diterima antara diantaranya faktor agama yang mengajarkan adanya penghargaan terhadap harkat dan martabat, persamaan derajat, dan menjunjung tinggi keadilan dalam hal hukum. ${ }^{4}$ Tidak ada manusia yang rela martabat dan harga dirinya direndahkan, diperlakukan tidak adil dan diskriminasi. Disinilah Islam mengajarkan kepada umatnya agar menjadi rahmat bagi seluruh alam.

Menyikapi segala perbedaan yang ada di Indonesia, sangat diperlukan adanya terobosan baru di dunia pendidikan khususnya pendidikan Islam. mengingat pendidikan adalah sektor yang paling berperan dalam menentukan keajuan bangsa. Maka tulisan ini berupaya menjelaskan seperti pendidikan islam yang diharapkan bangsa Indonesia saat ini? Hal ini dapat diformulasikan dengan judul Sistem Pendidikan Islam Dalam Kerangka Nasionalis-Religius Berbasis Rahmatan Lil Alamin.

\section{B. Pembahasan}

Kemunculan pendidikan Islam bersamaan dengan munculnya Islam itu sendiri. Islam diturunkan Allah SWT kepada Rasulullah SAW untuk seluruh manusia agar memperoleh kebahagiann dunia dan akhirat. Pendidikan Islam berdasar al-Qur'an dan As-Sunnah. Mir

\footnotetext{
${ }^{1}$ Whandi Pratama Putra Sisman, Dkk., Pendidikan Kwarganegaraan Bingkai NKRI, (Jakarta: Mitra Wacana Media, 2016), hlm. 41.

${ }^{2}$ Ibid., hlm. 46-49

3 Abdul Kodir, Sejarah Pendidikan Islam, (Bandung: Pustaka Setia, 2015), hlm. 150-153.

${ }^{4}$ Ibid., hlm. 147-148
} 
Aneesuddin dalam bukunya, Buku Saku Ayat-Ayat Semesta, menjelaskan bahwa al-Qur'an sebagai kitab terakhir yang topik-topiknya mengesankan manusia sepanjang waktu dan sesuai standar intelektual.

al-Qur'an merupakan kitab petunjuk bagi umat manusia, baik urusan dunia maupun akhirat. Maka sudah semestinya manusia melakukan pembelajaran dan pengkajian mendalam tentang al-Qur'an untuk di jadikan pedoman hidup. Alqur'an yang masih bersifat global membutuhkan penjelasan yang lebih terinci, oleh karenanya rasulullah diutus untuk menjelaskan isi kandungan al-qur'an sekaligus menjadi bagian hidupnya. Sehingga akhlak Rasulullah adalah al-Qur'an, Khuluquhu Al-Qur'an.

\section{Rasulullah Sebagai Rahmat}

Rasulullah diutus oleh Allah untuk menjadi rahmat bagi seluruh alam. Oleh sebab itu datangnya islam bukan hanya mengajarkan ibadah dalam ranah vertikal saja, lebih dari itu islam mengajarkan bagaimana menjalin hubungan yang harmonis, baik antar sesama manusia, maupun dengan makhluk lainnya. Hal ini ditegaskan dalam al-qur'an surah alanbiya ayat 107 ,



Dan Tiadalah Kami mengutus kamu, melainkan untuk (menjadi) rahmat bagi semesta alam (Q.S. Al-Anbiya/21: 107).

Quraish Shihab memandang ayat ini memiliki empat hal pokok yang harus dimengerti, yaitu adanya utusan Allah dalam hal ini Rasulullah Muhammad SAW., ada yang mengutus yakni Allah SWT., yang diutus kepada mereka seluruh yakni alam, dan risalah, yaitu rahmat yang bersifat luas. ${ }^{6}$ Menurutya bahwa Rasulullahmuhammad saw bukan sekedar membawa rahmat bagi seluruh alam namun justru kepribadian beliau lah yang menjadi rahmat. Begitu mulianya sifat RasulullahMuhammad sehingga Allah menyebutkan dengan pujian yang sangat agung.

Kemuliaan sifat Rasulullah tercermin dalam cara beliau berdakwah. Sehingga islam dikenal sebagai agama yang mengajarkan kepada kemaslahatan dunia dan akhirat. ${ }^{7}$ Usman abu bakar memahami pengertian rahmat pada diri rasul adalah ajaran tentang persamaan, persatuan dan kemuliaan umat manusia, hubungan sesama manusia, hubungan sesama pemeluk agama, dan hubungan antaragama. ${ }^{8}$ Rasulullah mengajarkan untuk saling menghargai, saling menolong, menjaga persaudaraan, perdamaian, dan sebagaianya. Lebih dari itu, Rasulullah juga mengajarkan etika terhadap binatang. Sehingga dalam melakukan

\footnotetext{
${ }^{5}$ Mir Aneesuddin. 2014. Buku Saku Ayat-Ayat Semesta. (Alih Bahasa: Machnun Husein). Jakarta: Zaman.
} h. 12

\footnotetext{
${ }^{6}$ Quraish Shihab, Tafsir Al-Mishbah, (Jakarta: Lentera Hati, 2002), hlm. 519

${ }^{7}$ Al-maraghi

${ }^{8}$ Usman abu bakar hlm. 65
} 
sembelihan binatang pun diajarkan cara-cara yang maslahat dan tidak menyakiti binatang.

Allah memang telah memilih dan mendidik Rasulullah sehingga memiliki sifat terpuji. Sebagaimana dalam surah ali imran disebutkan,

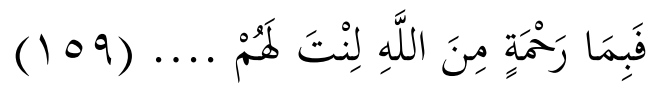

Maka disebabkan rahmat dari Allah-lah kamu Berlaku lemah lembut terhadap mereka (Q.S. Ali Imran/3: 159)

Ayat ini menurut Quraish Shibab sebagai bukti bahwa Allah lah yang telah mendidik Rasulullah secara langsung. Bukan hanya pengetahuan yang beliau terima namun kalbu yang penuh dengan kebaikan bahkan secara total wujud beliau menjadi rahmat bagi seluruh alam. ${ }^{9}$

Seluruh sifat dan sikap Rasulullahadalah bentuk dari implementasi tujuan disyariatkannya agama islam. Hal ini menjadi tanggung jawab pendidikan islam dalam meneruskan perjuangan Rasulullahsehingga dapat menciptakan keharmonisan dalam kehidupan masyarakat dan negara. Oleh karenanya Usman menyarankan agar kurikulum sebagai alat pendidikan tidak hanya terbatas pada tingaktan teoritis, namun sampai pada tahap implementasinya. ${ }^{10}$

\section{Rasulullah Sebagai Pendidik}

Seluruh dunia telah mengetahui keberhasilan Rasulullah membawa masyarakat jahiliyah menjadi masyarakat yang penuh dengan keimanan. Keberhasilan ini tentu tidak lepas dari pendekatan maupun metode beliau dalam berdakwah. Hal ini lah yang perlu dikaji dan diimplementasikan dalam dunia pendidikan saat ini.

Misi pendidikan Islam masa Rasulullah sebagaimana dijelaskan oleh Usman Abu Bakar; Pertama, Rasulullah memberikan motivasi akan kesadaran belajar dan mengajar. Kedua, program belajar sepanjang hayat. Ketiga, melakukan program pendidikan anak usia dini. Keempat membawa manusia dari kegelapan menuju kepada cahaya. Kelima, mengentaskan sikap jahiiyah masyarakat menjadi ketauhidan. Keenam, menyelamatkan kerusakan yang disebabkan karena pertikaian. Ketujuh, memanusiakan manusia dengan mengakui kesempurnaannya, mengangkat harkat dan martabatnya." Jika dipelajari satu persatu dari misi pendidikan tersebut, dapat disimpulkan bahwa pendidikan Islam tidak hanya mendidik peserta didik menjadi cerdas, namun pendidikan Islam harus mampu menjadi penggerak sekaligus pedoman dalam segala bidang. Dengan demikian keharmonisan dalam masyarakat akan terbina, karena seluruh manusianya memiliki pemahaman dan kesadaran yang sama. Yakni pemahaman terhadap aturan-aturan kehidupan sesuai syariat Islam. dan kesadaran akan persamaan di antara makhluk hidup sehingga tidak ada yang saling menindas dalam memenuhi kebutuhan hidupnya.

Out put dari proses pendidikan islam yang diharapkan adalah terciptanya manusia yang berakhlakul karimah. Rasulullah tidak saja menjadi pendidik yang profesional, akan

\footnotetext{
${ }^{9}$ Qurais shihab,,,hlm. 519

${ }^{10}$ Usman abu bakar, pendidikan islam pluralis multukultural, hlm. 75

${ }^{11}$ Usman Abu Bakar, hlm. 66-72
} 
tetapi keluhuran akhlaknya menjadikan masyarakat kafir quraisy saat itu kagum sehingga memeluk agama islam. Bagaimanapun keberhasilan pendidikan sangat bergantung pada pendidik. Oleh karenanya setiap pendidik dituntut untuk memiliki kemampuan yang mumpuni. Ramayulis menyederhanakan, pendidik dalam pendidikan islam setidaknya memiliki beberapa hal yaitu, Pertama, komitmen terhadap mutu perencanaan, proses dan hasil pendidikan. Kedua, memiliki akhlakul karimah sebagai uswah bagi peserta didik. Ketiga, ikhlas dalam menjalankan tugasnya. Keempat membangun jaringan dengan berbagai pihak dalam rangka meningkatkan mutu pendidikan. ${ }^{12}$ Kompetensi inilah yang sering dikenal dengan kompetensi pedagogik, personal, profesional dan sosial. Setidaknya keempat kompetensi itu ada para diri seorang pendidik agar berpeluang besar memperoleh keberhasilan dalam melaksanakan tugas mendidik.

\section{Pendidikan Islam dalam Konteks Kebangsaan}

a. Definisi dan Tujuan Pendidikan Islam

Banyak pendapat para ahli menyebutkan definisi pendidikan islam yang secara redaksi berbeda-beda, namun esensi dan penekanannya sebenarnya sama. Ahmad Tafsir mislanya mendefinisikan pendidikan islam adalah bimbingan seseorang atas orang lain agar bekembang maksimal sesuai dengan ajaran islam, sehingga menjadi muslim sempurna. ${ }^{13}$ Kesempurnaan tidak hanya terbatas pada intelektual saja, namun emosional dan spiritual. Lebih lanjut $\mathrm{m}$. Yusuf al-Qardawi mendefinisikan pendidikan islam adalah pendidikan manusia seutuhnya, yakni keseimbangan akal dan hati, jasmani dan ruhani, dan akhlak bersama dengan keterampilannya. ${ }^{14}$ Ramayulis mendefinisikan pendidikan islam sebagai proses dari upaya ikhtiyar manusia yang mencakup wujud manusia seutuhnya, baik jasmani maupun rohaninya. ${ }^{15}$

Dari ketiga pendapat di atas nampaknya secara redaksi memang ada sedikit berbeda, namun secara esensi ketiganya memiliki kesamaan. Sehingga pendidikan islam dapat difahami sebagai proses mengembangkan potensi peserta didik seutuhnya berdasarkan ajaran islam. Setelah mengikuti proses pendidikan peserta didik nantinya akan menjadi insan yang paripurna, sehat jasmani, akal, hati, memiliki akhlak yang mulia, pengetahuan yang luas, dan keterampilan yang memadai dalam mengelola bumi sebagaimana tugasnya menjadi khalifah Fi Al-Ard.

Pendidikan islam diharapkan dapat memayungi segala pendidikan yang ada. Oleh karenanya pendidikan islam harus mampu mewujudkan apa yang menjadi tujuan ke depan sesuai dengan kebutuhan pasar. Tujuan pendidikan islam sebagaimana disampaikan dalam bukunya Usman Abu Bakar paradigma dan epistemologi pendidikan islam adalah

Menyiapkan gernerasi islam terdidik yang beriman dan berakwa kepada Allah SWT memiliki kesiapan dan kecakaan untuk berkembang di zamannya cakap dan cukup

\footnotetext{
${ }^{12}$ Ramayulis, Filsafat Pendidikan Islam, hlm. 222

${ }^{13}$ Ahmad tafsir, ilmu pendidikan dalam perspektif islam, (bandung: remaja rosdakarya, 2000), hlm. 32

${ }^{14}$ M.yusuf al-qardhawi, pendidikan islam dan madrasah hasan al-banna, (jakarta: bulan bintang, 1980), hlm, 94

${ }^{15}$ Ramayulis, filsafat pendidikan islam, hlm. 121
} 
ilmu serta amaliahnya dilandasi dengan ak-qur'an dan sunnah. ${ }^{16}$

Pernyataan Usman tersebut dapat dipahami bahwa islam adalah agama yang relevan dengan karakter, tingkat perkembangan dan tuntutan manusia. Tidak benar jika ada yang mengatakan kalau islam menghambat perkembangan manusia dalam menghadapai segala persolan di zamannya. Justru islam adalah sumber ilmu sekaligus spirit bagi pemeluknya untuk menggali kedalaman ilmu sedalam-dalamnya melalui kitab suci al-Qur'an dan sunnah dalam upaya menghadapi segala tantangan mendatan.

Sebagaimana telah diketahui bahwa sumber pendidikan islam adalah al-Qur'an dan sunnah. Di atas telah dijelaskan bahwa islam mengajarkan kepada umatnya untuk saling menghormati, menghargai, menegakkan keadilan, dan menjunjung tinggi harkat dan martabat kemanusiaan. Manusia diciptakan sama yang membedakan adalah ketakwaannya.

Mengacu pada prinsip ajaran islam sendiri maka pendidikan islampun harus mampu menghasilkan lulusan sebagaimana dikehendaki ajaran islam. Rasulullah adalah seorang Rasul sekaligus pendidik yang dapat menjadi tauladan dalam menyampaikan pendidikan. Perkataan, sikap, dan wujudnya adalah rahmat bagi seluruh alam. Cukup kiranya jika sebagai pemerhati pendidikan islam menjadikan sosok sempurna itu sebagai acuan dalam merumuskan sistem pendidikan islam.

\section{b. Pendidikan Islam dan Kebangsaan}

Problematika yang sering terjadi di masyarakat saat ini dapat mengancam keutuhan bangsa Indonesia. Permasalah yang muncul saat ini tdiak saja gesekan antar umat beragama, namun hampir di semua sektor. Pemangku keagamaan maing-masing mempertahankan ideologinya sehingga para orang awam pun ikut-ikutan dengan segala luapan emosinya. Pemangku kekuasaan yang dipercaya untuk mengelola stabilitas negara sebagian menghianati amanahnya dengan gencarnya korupsi di mana-mana. Dan masih banyak problematika lain yang dapat mengancam keutuhan republik Indonesia.

Kemerdekaan Indonesia tidak lepas dari eksistensi islam di dalamnya. Hal ini dibuktikan banyaknya pejuang bangsa dari kalangan ulama, seperti Imam Bonjol, Hadratus Syaikh Hasyim Asy'ari, Kyai Abbas Buntet dan sebagainya. Mereka tidak hanya berjuang secara fisik menyerang penjajah, namun bagaimana agar masyarakat Indonesia menjadi masyarakat beriman, bertakwa, cerdas, dan siap menghadapi tantangan di kemudian hari. Ini lah salah satu kebangkitan jiwa nasionalisme atau semangat kebangsaan yang tinggi.

Setelah kemerdekaan Indonesia dirumuskan pancasila sebagai dasar Negara Republik Indonesia. Isi dari pancasila sendiri mengandung nilai-nilai ajaran islam. Pancasila sebagai ideologi, falsafah dan pandangan hidup kebangsaan memuat nilai-nilai ketuhanan, kemanusiaan, kesatuan, kerakyatan dan permusyawaratan. Nili-nilai ini jika disandingkan dengan konsep keislaman akan terjadi keserasian dan melengkapi. ${ }^{17}$

Sila pertama mengarahkan kepada keimanan dan ketakwaan kepada Allah sebagai Sang Maha Pencipta yang tunggal. Hal ini menjadi salah satu tujuan pendidikan islam, yaitu

\footnotetext{
${ }^{16}$ Usman Abu Bakar, hlm. 79

${ }^{17}$ Achmad Siddiq, Islam, Pancasila, Dan Ukhuwah Islmaiyah, (Jakarta: Lajnah Ta'lif Wan Nasyr PBNU, 1985), hlm. 12
} 
menjadikan peserta didik beriman dan bertaqwa. Sesuai dengan fieman Allah surah alIkhlash

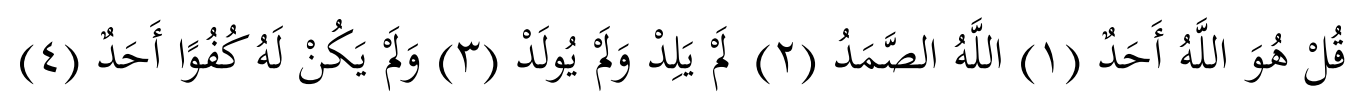

Katakanlah: "Dia-lah Allah, yang Maha Esa. Allah adalah Tuhan yang bergantung kepada-Nya segala sesuatu. Dia tiada beranak dan tidak pula diperanakkan,. dan tidak ada seorangpun yang setara dengan Dia."

Sila kedua kemanusiaan yang adil dan beradab mengakui adanya kesamaan manusia sebagai makhluk Tuhan yang memiliki kesamaan derajat, pengakuan kemerdekaan atas segala bangsa dan menolak kolonialisme dan imperialisme. ${ }^{18}$ Hal ini tidak lepas dari ajaran islam yang terdapat dalam al-Qur'an Surah al-Maidah ayat 8:

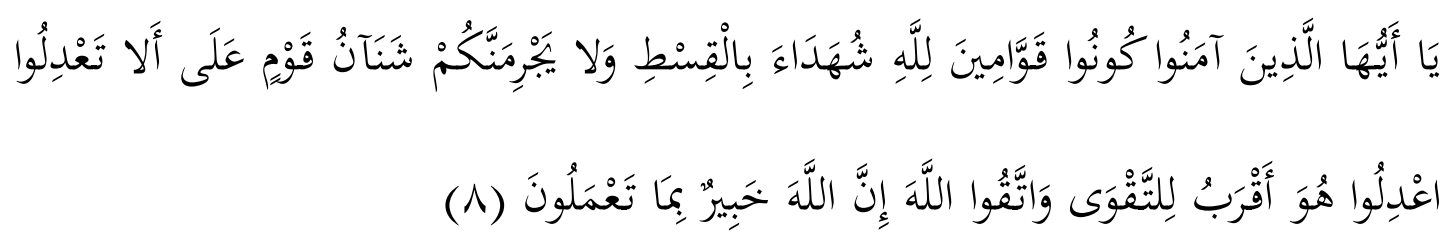

Hai orang-orang yang beriman hendaklah kamu Jadi orang-orang yang selalu menegakkan (kebenaran) karena Allah, menjadi saksi dengan adil. dan janganlah sekali-kali kebencianmu terhadap sesuatu kaum, mendorong kamu untuk Berlaku tidak adil. Berlaku adillah, karena adil itu lebih dekat kepada takwa. dan bertakwalah kepada Allah, Sesungguhnya Allah Maha mengetahui apa yang kamu kerjakan. (Q.S. Al-Maidah/5: 8).

Sila ketiga persatuan Indonesia merupakan dasar sikap yang mengutamakan kepentingan bangsa di atas kepentingan suku, golongan, partai dan lain-lain. ${ }^{19}$ Konsep persatuan ini merupakan bagian dari ajaran islam sebagaiman Allah perintahkan dalam alQur'an Surah Ali Imran ayat 103

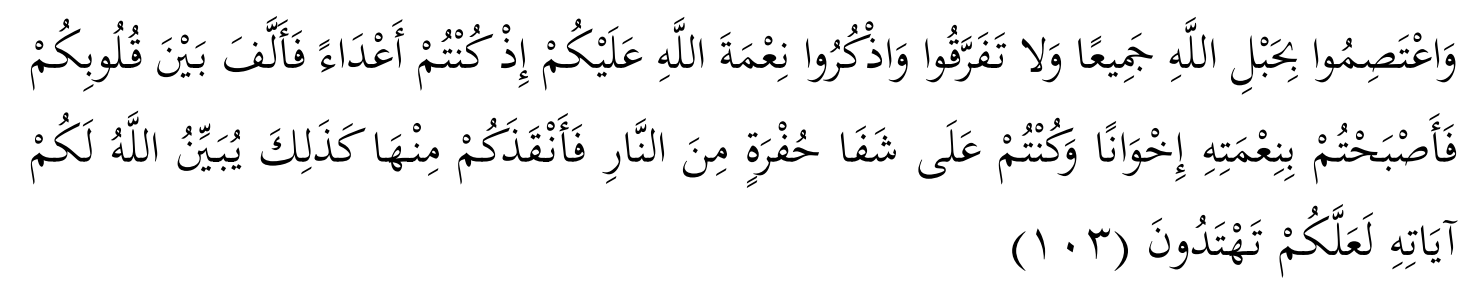

Dan berpeganglah kamu semuanya kepada tali (agama) Allah, dan janganlah kamu bercerai berai, dan ingatlah akan nikmat Allah kepadamu ketika kamu dahulu (masa Jahiliyah) bermusuh-musuhan, Maka Allah mempersatukan hatimu, lalu menjadilah kamu karena nikmat Allah, orang-orang yang bersaudara; dan kamu telah berada di tepi jurang neraka, lalu Allah menyelamatkan kamu dari padanya. Demikianlah Allah

18 Samsul Wahidin, Dasar-Dasar Pancasila Dan Kewarganegaraan, (Yogyakarta: Pustaka Pelajar, 2015), hlm. 14

${ }^{19}$ Ibid., hlm. 15 


\section{Journal of Islam and Muslim Society}

Vol 1 No 1 (2019)

menerangkan ayat-ayat-Nya kepadamu, agar kamu mendapat petunjuk. (Q.S. Ali $\operatorname{Imran} / 3:$ 103).

Sila keempat kerakyatan yang dipimpin oleh hikmat kebijaksanaan dalam permusyawaratan perwakilan. Kedaulatan rakyat terwujud dalam hak asasi manusia seperti dalam hal mengeluarkan pendapat, hak berkumpul, hak ikut serta dalam pemerintahan, dan sebagainya. Hal ini sesuai dengan jiwa pancasila yang bersifat musyawarah dan mufakat serta tenggang rasa atas dasar kerakyatan yang dipinpin oleh hikmat kebijaksanaan dalam permusyawaratan perwakilan. ${ }^{20}$

Sebuah organisasi baik kecil ataupun lingkup besar tentu membutuhkan pemimpin sebagai wakil dari anggota. Begitupun suatu negara tentu membutuhkan peran pemimpin sebagai wakil rakyat dalam mewujudkan cita-cita bersama. Oleh karenanya Islam mengajarkan kepatuhan kepada pemimpin dan tunduk dalam kebenaran.

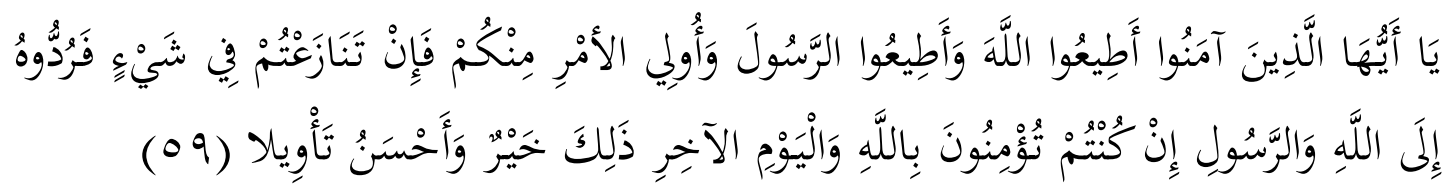

Hai orang-orang yang beriman, taatilah Allah dan taatilah Rasul (Nya), dan ulil amri di antara kamu. kemudian jika kamu berlainan Pendapat tentang sesuatu, Maka kembalikanlah ia kepada Allah (Al Quran) dan Rasul (sunnahnya), jika kamu benarbenar beriman kepada Allah dan hari kemudian. yang demikian itu lebih utama (bagimu) dan lebih baik akibatnya. (Q.S. An-Nisa/4: 59).

Sila kelima keadilan sosial bagi seluruh rakyat Indonesia mengandung makna keadilan yang memberi pertimbangan dengan pemahaman bahwa hak milik berfungsi sosial. ${ }^{21}$ Rakyat indonesia memiliki hak yang sama atas kesejahteraan, pendidikan, pengakuan dan kebebasan berekspresi. Dalam arti kebebasan yang tidak bertentangan dengan norma-noram agama maupun pancasila.

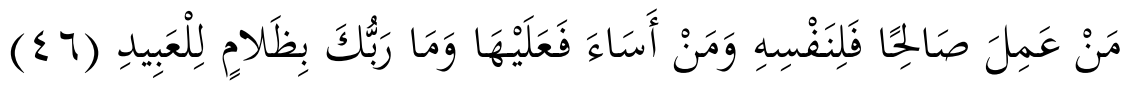

Barangsiapa yang mengerjakan amal yang saleh Maka (pahalanya) untuk dirinya sendiri dan Barangsiapa mengerjakan perbuatan jahat, Maka (dosanya) untuk dirinya sendiri; dan sekali-kali tidaklah Rabb-mu Menganiaya hamba-hambaNya (Q.S. Fushilat/41: 46).

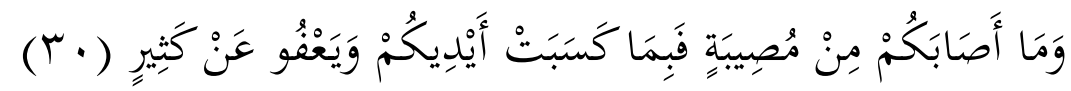

dan apa saja musibah yang menimpa kamu Maka adalah disebabkan oleh perbuatan tanganmu sendiri, dan Allah memaafkan sebagian besar (dari kesalahan-

${ }^{20}$ Ibid., hlm. 16-17

${ }^{21} \mathrm{Ibid}$, hlm. 17 
kesalahanmu) (Q.S. Asy-Syuura/42: 30).

Manusia hidup beragama dan berbangsa. Keduanya menjadi satu kesatuan dalam dirinya. Agama mengatur segala aspek kehidupan termasuk hubungan vertika dan juga hubungan horisontal atau sesama makhluk. Yang menjadi pertanyaan besar dalam kehidupan saat ini adalah mengapa masih saja terjadi adanya pemisahan antara kepentingan agama dan negara. Orang yang mengikuti aturan negaranya dianggap tidak sesuai dengan apa yang diajarkan agama (Islam).

Jika hal ini dibiarkan terus menerus maka bukan saja rakyat umum yang menjadi korban, namun persatuan antar suku, bangsa bahkan antar negara pun terancam. Di sinilah pentingnya optimalisasi pendidikan islam sesuai dengan apa yang telah dibawa oleh Rasulullah sebagai rahmat bagi seluruh alam. Sistem Pendidikan Islam harus membumikan karakter Rasulullah sebagai rahmat sekaligus pendidik dalam kurikulumnya. Sehingga lulusan yang dihasilkan diharapkan adalah sosok yang cerdas, arip, bijaksana dan cinta akan damai. Ketika kenyamanan dan ketenteraman sudah dirasakan oleh rakyat indonesaia maka dimungkinkan akan tercipta kehidupan yang harmonis. Inilah arti kemerdekaan yang sesungguhnya, kebebasan dari segala aspek manusiawi.

Peningkatan mutu pendidikan islam menjadi tanggung jawab lembaga-lembaga pendidikan islam baik formal maupun non formal, mulai dari tingkat dasar hingga perguruan tinggi. Maka lembaga pendidikan islam perlu berbenah diri dalam hal kurikulum yakni kurikulum yang mengandung unsur Rahmatan Lil Alamin.

\section{Daftar Pustaka}

Abu Bakar, Usman. 2013. Paradigma Dan Epistemologi Pendidikan Islam, UAB MEDIA 2003. Pendidikan Islam Pluralis Multukultural, UAB MEDIA

Al-Qardhawi, M. Yusuf. 1980. Pendidikan Islam Dan Madrasah Hasan Al-Banna, Jakarta: Bulan Bintang.

Aneesuddin, Mir. 2014. Buku Saku Ayat-Ayat Semesta. Alih Bahasa: Machnun Husein. Jakarta: Zaman.

Kodir, Abdul. 2015. Sejarah Pendidikan Islam, Bandung: Pustaka Setia.

Ramayulis, 2015. Filsafat Pendidikan Islam, Jakarta: Kalam Mulia.

Shihab, Quraish. 2002. Tafsir Al-Mishbah, Jakarta: Lentera Hati, 2002.

Siddiq, Achmad. 1985. Islam, Pancasila, Dan Ukhuwah Islmaiyah, Jakarta: Lajnah Ta'lif Wan Nasyr PBNU.

Tafsir, Ahmad. 2000. Ilmu Pendidikan Dalam Perspektif Islam, Bandung: Remaja Rosdakarya.

Wahidin, Samsul. Dasar-Dasar Pancasila Dan Kewarganegaraan, Yogyakarta: Pustaka Pelajar, 2015.

Whandi Pratama Putra Sisman, Dkk., 2016. Pendidikan Kwarganegaraan Bingkai NKRI, Jakarta: Mitra Wacana Media. 